\title{
Impact of Driver Age and Experience in Software Usage on Driving Safety and Usability of Car-Sharing Software
}

\author{
Chunhui Jing $\mathbb{D}^{1},{ }^{1}$ Jinyi Zhi $\mathbb{D},{ }^{1}$ Suixian Yang $\mathbb{D}^{2},{ }^{2}$ and Wei Wang $\mathbb{D}^{3}$ \\ ${ }^{1}$ School of Architecture and Design, Southwest Jiaotong University, Chengdu 611756, China \\ ${ }^{2}$ College of Mechanical Engineering, Sichuan University, Chengdu 611065, China \\ ${ }^{3}$ College of Design, Georgia Institute of Technology, Atlanta, CO 30314, USA \\ Correspondence should be addressed to Chunhui Jing; jingch@swjtu.edu.cn
}

Received 16 November 2020; Revised 26 January 2021; Accepted 12 May 2021; Published 21 May 2021

Academic Editor: Jaeyoung Lee

Copyright ( $\odot 2021$ Chunhui Jing et al. This is an open access article distributed under the Creative Commons Attribution License, which permits unrestricted use, distribution, and reproduction in any medium, provided the original work is properly cited.

Car-sharing economy has caused new driving safety and usability problems, which have not been well studied. This study aims at analyzing the effects of users age and the user experience (UX) of the car-sharing software (e.g., DiDi travel app) on overall usability and the level of distraction for drivers. To this end, 48 experienced Chinese drivers were recruited to perform various tasks with the car-sharing software using a driving simulator. The variables of driving safety and usability were analyzed by twoway analysis of variance (ANOVA) and independent sample Kruskal-Wallis nonparametric test. As expected, it was found that car-sharing software has a significant negative impact on driving distraction and usability. The overall performance of young drivers is better than that of the elderly, but it seems that young drivers are more likely to be led to errors by car-sharing software. In most aspects, experienced drivers perform better than inexperienced drivers and have a better in-depth understanding of carsharing software weaknesses. However, inexperienced drivers performed better regarding braking time and interaction time. Although young inexperienced drivers performed worst in driving safety, they exhibited the lowest cognitive load and the highest interaction efficiency. The experience of using car-sharing software may improve driver's ability to deal with driving distractions. The above conclusions provide theoretical support for optimizing the UX of car-sharing software and some references for driver's screening and training.

\section{Introduction}

When driving, the use of mobile phones is common in such countries as Sweden, Australia, the United States, the United Kingdom, and Spain [1-3]. Nowadays, due to the emergence of a car-sharing economy known as the "Gig Economy" [4], a new scenario of mobile phone usage in the car emerged. As mentioned in the "Annual report on the development of China's sharing economy in 2019," which was published by the China National Information Center-Sharing Economy Research Center, there was an increase in the amount of online taxi passengers during 2015-2018 from 9.5 percent to 36.3 percent. By the end of 2018, DiDi travel (China's most extensively used car-sharing software, functioning extremely similar to Uber) has connected over 450 million passengers and 21 million drivers, receiving 7.43 billion orders and completing over 25 million orders daily, and served over 400 cities [5]. Nevertheless, the behavior of using mobile phones during driving (MPDD) seriously affects driving safety [6-8], and due to the short appearance of the car-sharing model, the previous research on MPDD mostly focused on tasks such as dialogue/dial-up/texting [9]. As another usage scenario of MPDD, limited research has been conducted on car-sharing software tasks. However, Jing et al. [10] and Feng et al. [11] reported that car-shared tasks have affected safety and software usability, which indicated that it is necessary and significant to research on car-sharing applications.

Among the factors that have affected the in-car application of car-sharing software, we propose analyzing the aspects of driver age on performance in using car-sharing software. Aging populations are a global trend, and China is no exception [12-16], with the number of elderly drivers 
significantly increasing in the future. However, to the best of our knowledge, there has been no research on driving safety and phone usage in terms of driver age in car-sharing, which is an essential aspect for the screening and training of drivers. According to statistics, young drivers are more likely to use mobile phones than older people during driving. Simultaneously, the proportion of younger people in-car accidents is exceedingly high. Lesch and Hancock [17] showed that age has different effects on driving confidence and performance when subjects are distracted by simulated mobile tasks. When attention is distracted in complex cognitive tasks, older people perform worse than their younger counterparts [18]. It was reported that older drivers responded slower to tasks involving phones [19]. Haque and Washington [20] observed that each additional year of drivers' age increases $12 \%$ reaction time, while another study found that response times were affected by 0.18 seconds more in elderly drivers than younger ones [21]. Additionally, the elderly are more likely to be affected when talking on the phone while driving [22]. A study in Wuhan, China, reported that older adults were more likely to be influenced by in-car phone interaction [23]. Nevertheless, not all studies on the risks of using mobile phones while driving are consistent [24]. Some studies in India and China have demonstrated that age exerts no significant impact on short messages and telephone calls while driving [25]. However, the effect of age on car-sharing software, as another situation of mobile phone usage in the car, remains unclear, thereby necessitating further research in this regard.

Additionally, one would assume that new and experienced drivers who join the car-sharing industry differ in driving safety and app usability. Previous research has shown that driving experience impacts driving safety and app usability $[26,27]$. However, further research is required to understand to what extent experience affects these two factors entirely. Moreover, the knowledge gained by an indepth study on the safety and ability to use the car-sharing app would provide priceless insight for training and screening purposes.

To sum up, in the context of an aging society and the uneven level of driver experience, there is still a lack of research on the age and experience of car-sharing drivers. Because of the necessity of driving safety and the urgency of screening and training car-sharing drivers, age and experience are selected as the independent variables.

Furthermore, it is necessary to conduct "two-way" research on driving safety and interactive usability. "Two way" research means that it is essential not only to study the driving safety problems caused by the use of car-sharing software in the car but also to explore the "reverse effect": the impact of driving tasks on the interactive performance of shared tasks $[28,29]$. Previous research mainly focused on mobile phones in the car and the impact on driving safety. For example, the effect of performing music search or navigation tasks on the driver's visual attention and driving ability has been studied [30-32]. The impact of hands-free and handheld mobile phones on driving performance has been compared. It has found that using the mobile phone in the vehicle will increase response time $[33,34]$, impair visual attention distribution $[35,36]$, reduce lane change frequency $[37,38]$, increase the distance following [39], and reduce driving speed $[40,41]$. These disturbances will lead to an increase in driving safety risks. More concretely, the following parameters are often used to measure driving safety: Reimer et al. pointed out that driver behaviors are often measured by speed selection [42]. Drivers who are distracted by mobile phone conversations are reported to choose lower driving speeds, with higher variability and higher lateral acceleration [23]. Talking/dialing/texting while driving will reduce driving speeds [9]. The braking response time was also used to reflect the degree of driving distraction $[43,44]$. For example, conversations, texting, and using a handheld phone while driving would increase braking time $[45,46]$. Nabatilan et al. reported that drivers using mobile phone conversations would make more driving errors and irregularities [47]. Soccolich et al. discovered that the driver's cognitive load generally increases under all dual-task conditions associated with MPDD [48]. Moreover, some studies have reported that mobile phone interactions lead to increased corrections in both directions of the steering wheel $[9,49]$. On the other hand, in recent years, there have been some studies on the reverse effect, i.e., the impact of driving tasks on mobile phone tasks [9]. Becic et al. [29] reported that dual tasks, such as talking through a mobile phone, could affect driving performance and dialogue performance at the same time. According to Cao et al. [28], keeping lanes will reduce speech comprehension. Tractinsky et al. [26] found that driving affects mobile phone response time. Spence et al. [50] reported more challenging cognitive tasks to influence the accuracy of driver dialogue. At the same time, driving tasks also affected the accuracy of texting. However, as Oviedo trespacios [9] pointed out, the research about usability was still much less than the research about driving safety. Therefore, "two-way" analysis helps examine the cross-influence of car-sharing tasks and driving tasks on the whole.

In terms of research methods, driving simulators are commonly used for in-car interaction research [51]. Although it claimed that the driving simulator lacks realism [9], it is safe and convenient to control the driving parameters [49] and is quite effective even when compared with real driving [52]. Some studies also conduct driving experiments in actual vehicles, that is, "Naturalism" research. However, naturalism research is relatively expensive, and the number of subjects and experimental scenes is limited [34]. Thus, the present study intends to use a driving simulator for the experiment. In driving simulator-related research, $44 \%$ of articles applied analysis of variance (ANOVA) to determine the difference between distracted and undistracted driving performance and other parameters of interest [9]. Hence, a two-way analysis of variance was used in the present work for data analysis.

As stated by Choudhary et al. [24], the current studies on the interfering impact of mobile phones had been mostly carried out in developed countries, and there are a few numbers of works conducted in developing countries. However, developing countries account for $80 \%$ of the world's population, and they have strong economic growth 
potential. In recent years, the number of cars and mobile phones in developing countries has been expanding rapidly [10]. In developing countries, reasons such as insufficient traffic laws, weak law enforcement capabilities, insufficient residents' experience with smartphones, different traffic environments, and others have led to different driving styles and habits (for example, in low- and middle-income countries, horn sound is more popular than in high-income countries) [53]. The problems and consequences of mobile phones in vehicle driving are even more serious [1]. Also, racial, customary, and cultural factors will cause different results in interactive and driving performance. For instance, Nakano et al. [54] indicated the difference between American and Japanese participants in search habits and search speed. Hence, it suggested that an investigation in China (as the most populous developing country) can provide interesting findings.

Notably, car-sharing driver's age and user experience could exhibit different safety and interaction performance while operating car-sharing software. The research on how driver's age and experience affects driving safety and interaction performance could reference for targeted software design or preemployment training for different user groups, which could help prevent safety risks, enhance training effect, and decrease training costs. However, there is still a lack of relevant research, and this article intends to use simulation experiments to analyze the age (old, young) and the user experience (experienced, inexperienced) variables of drivers in three typical car-sharing software tasks (ordering, information check, and destination search). Specifically, the present study aims at:

(1) The influence of driver's age on driving safety and the ability to interact with car-sharing software

(2) The effect of driver's experience in using the relevant car-sharing software

\section{Materials and Methods}

2.1. Participants. Regarding the "DiDi Employment Report 2019" [55] released in 2019, 92.3\% of sharing car drivers are males, and Oviedo-Trespalacios et al. [9] reported that gender could affect in-car interaction; thus, to eliminate the influence of irrelevant variables as much as possible, the participants in this study were all males. Additionally, to exclude the impact of chirality on the research, right-handed participants were selected. Therefore, the research subjects were defined as right-handed men.

Previous works often used an age range for young drivers of 25 to 30 years old, while the ages of elderly drivers varied from 50 to $75[16,56]$. Thus, we define young drivers in this study as those between 18 (driving age allowed in China) and 30 years old (mean: 28.4, SD: 5.2), while elderly drivers age was defined as 50-65 (the legal retirement age in China) years old (mean: 55.3, SD: 6.5). Moreover, based on the definition provided by Zhao et al. [57], the term "experienced" for the drivers was defined as driving over three times per week and over $10 \mathrm{~h}$ per day for over 5 years. Conversely, "inexperienced" means no use of car-sharing software.
48 drivers were recruited for this work. The participants were right-handed men and were divided into four groups: old-experienced, old-inexperienced, young-experienced, and young-inexperienced. The drivers were in good health with no reported vision problems, and all operated small manual cars. The age and joining time of the driver can be checked in the online chat group of DiDi drivers. For drivers in 10 online chat groups, we selected participants based on age and experience data through a proportional stratified sampling method. The recruitment information was released on the Internet communication chat group gathered by $\mathrm{DiDi}$ travel drivers. First, an online appointment was made, and then an offline experiment was conducted to recruit participants. The reward for each participant was $\$ 15 /$ person/ hour.

2.2. Apparatus and Testing Environment. For conducting the experiments, the simulator was used (Figure 1). The driving simulator includes a desktop computer equipped with a Windows 7 professional operating system, a 27-inch LCD monitor (Dell D2720DS, digital window communication) with a resolution of $2560 \times 1440$ and a refresh rate of $60 \mathrm{HZ}$, a steering wheel, shift gear and pedals (Logitech G27, Figure 1), and camera (SONY HDR-CX680). The simulated driving environment consists of a simulated road environment and driving software for real-time recording of driving data. The driving simulation software uses ErgoLAB Driver-Vehicle-Road and Environment Test Cloud Platform provided by Beijing JINFA Technology limited company. Regarding simulated road environment, two lanes have been used in the MPDD study in most of the experimental roads (approximately 62 percent), where the simulator scene is used [9]. Thus, a two-lane route was selected in the current study simulating Chinese cities as an experimental road. The light driving load was considered so that additional effects on the speed are avoided. $40-50 \mathrm{~km} / \mathrm{h}$ was the normal speed since the minimum speed limit of urban roads is $30 \mathrm{~km} / \mathrm{h}$ in China, and the maximum speed limit is $60 \mathrm{~km} / \mathrm{h} \mathrm{[58]}$. The simulated driving environment was displayed on the computer screen, which was $610 \mathrm{~mm}$ away from the participants' eyes. The driving data was mainly monitored by ErgoLAB Driver-Vehicle-Road and Environment Test Cloud Platform, including the driver's pedal behavior data (accelerator, brake, and clutch). The accuracy was $0.3 \%$ F.S, and the sensitivity was $1.5 \mathrm{mv} / \mathrm{v}$. Steering wheel rotation angle data, with steering wheel angle and torque data, were considered. The measuring range of the rotating torque was $0-300 \mathrm{Nm}$, and the measuring range of rotating angle was $0-3000^{\circ}$. On-Board Diagnostics (OBD) vehicle data, including vehicle speed and engine speed, were obtained.

The used screen mobile phone size was the Samsung Galaxy S5 (G9006 V) with a 5.7-inch touch $(1920 \times 1080$ pixels), which is currently the most mainstream smartphone screen size in China. The mobile phone was fixed at the most frequent locations (which was based on a presurvey of 30 experienced drivers using car-sharing software): the right air-conditioning outlet of the car through the mobile phone holder (which was $360 \mathrm{~mm}$ from the participant's body centerline). 


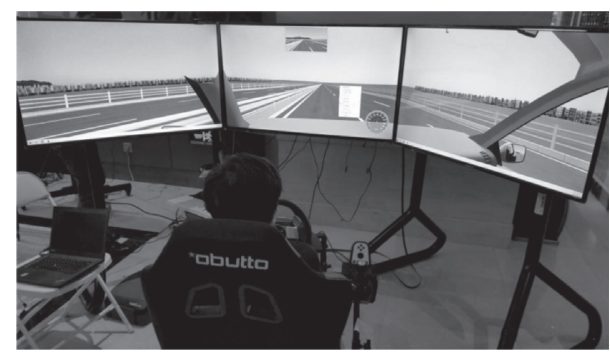

FIgURE 1: Experimental equipment.

In addition, NASA-TLX and the satisfaction questionnaires were used to investigate the participants subjective responses after the experiment. HD cameras and laptops were used for capturing audio and video material to record the driving scene and the participant's behavior interaction.

2.3. Experimental Design. Two independent factors (age and experience) were used in this experiment. The independent variables are the age of the drivers (young and old) and the driver's proficiency in using car-sharing software (experienced and inexperienced).

The usability variables and driving safety variables were the dependent variables. Driving safety variables were braking response/stop time, speed, cognitive load, and steering wheel correction amplitude/times, driving error. The speed is defined as follows: the car's average speed when drivers perform the task, collected through the ErgoLAB platform (sampling frequency: $20 \mathrm{HZ}$ ). The braking response time is defined as the time when the driver receives the deceleration signal and makes the braking action. The signal sending time is controlled and recorded by the researcher, and the ErgoLAB platform collects the pedaling time. Braking stop time is defined as the time taken to brake by the driver until the car speed is decelerated to $20 \mathrm{~km} / \mathrm{h}$, and the related data was collected through the ErgoLAB platform. The driving error is defined as the number of times the detected car passed the road baseline, which was counted by using video recordings facing the road baseline. The steering wheel correction amplitude/times are defined as the total number of times (the steering wheel amplitude exceeds $2^{\circ}$ to be counted) and the average angle (sampling frequency: $20 \mathrm{HZ}$ ) the driver adjusted the steering wheel when performing the interactive task, and data was collected through ErgoLAB platform. Cognitive load is determined by the NASA-TLX scale [59]. Usability variables are composed of the following factors: interaction time (efficiency), interaction error (effectiveness), cognitive load, and satisfaction. The interaction time is defined as the time that is needed for completing the task, and the experimental demo recorded the time. The satisfaction was determined using the USE Questionnaire [60], completed by participants after the experiment. The unsuccessful executions of an interaction task define the interaction error, which was observed and counted by the experimenter in the experiment.

\section{Experimental Tasks and Procedures}

3.1. Experimental Tasks. To simulate the interactive mode of car-sharing software (DiDi travel), first, the interactive process of car-sharing software was sorted out. 11 main functions were obtained in the process, including calling passengers, personal information, and ordering, as presented in Table 1. Then, participants (30 experienced drivers) ranked these functions based on whether they will be frequently used in driving. Their importance was measured by counting the frequency, with which each function is evaluated as "yes." Finally, the three most frequent functions were identified as follows: ordering (usage probability: $100 \%$ ); information check (passenger information, navigation, etc.) (usage probability: $87 \%$ ), and destination search (determining the screen location on the map outside the window by panning or zooming) (usage probability: 63\%). Accordingly, the Sketch software was used to develop three experimental demos with the identified functions, i.e., ordering, information check, and destination search for testing the user's performance in usability and driving safety (Figure 2).

3.2. Experimental Procedures. The experiment consisted of four steps and took about 50 minutes to complete:

(1) Collecting basic information about participants, including driving age, driver's age, gender, driving habits, car type, and car-sharing software experience.

(2) Informing participants about purpose, steps, driving, and interactive tasks and providing 15 minutes of training for them for familiarity with interactive and driving tasks. According to the independent variables, 48 participants were assigned into four groups. To avoid learning effects, a balanced Latin square presentation order was used. Each experimental condition was shown once to each participant. When participants completed the driving-interaction tasks, they were asked to complete the cognitive load and satisfaction scale. Before beginning the trial, participants were told: please drive according to your driving habits when the experiment runs (but they needed to make sure that their hands are on the steering wheel at 10 o'clock and 14 o'clock); unexpected situations may occur during driving (e.g., a sudden crossing of pedestrian, etc.); and the empirical tasks should be completed under the presumption of ensuring driving safety.

(3) After adjusting the mobile phone position and the seat position, in order to compare the different performances in the parked and driving conditions, first, the participants were tested on three tasks in the parked situation: T1/T2/T3. T1: ordering: the participant checked the text information shown on the phone screen upon hearing "Look." When the information was confirmed, he clicked the "Confirm" button, and by clicking the button, the message 
TABLe 1: Descriptive statistics of mean and standard deviation of interaction time among different ages and experience.

\begin{tabular}{llcccc}
\hline \multicolumn{1}{c}{ Group } & & \multicolumn{3}{c}{ Interaction time (s) } \\
& & T1 (parked) & T3 (parked) & T1 (driving) & T3 (driving) \\
\hline \multirow{2}{*}{ Old/Young } & Old & $11.29 \pm 3.40$ & $11.50 \pm 2.42$ & $21.51 \pm 7.63$ & $17.66 \pm 7.49$ \\
& Young & $7.30 \pm 2.27$ & $7.19 \pm 2.01$ & $7.52 \pm 2.05$ & $11.03 \pm 4.01$ \\
Experienced/Inexperienced & Experienced & $9.61 \pm 4.04$ & $9.26 \pm 2.90$ & $12.95 \pm 6.64$ & $18.93 \pm 6.33$ \\
Old-experienced & Inexperienced & $8.98 \pm 2.91$ & $9.42 \pm 3.34$ & $16.08 \pm 10.74$ & $9.76 \pm 3.34$ \\
Old-inexperienced & & $12.90 \pm 3.12$ & $11.59 \pm 1.63$ & $19.16 \pm 2.27$ & $23.13 \pm 6.60$ \\
Young-experienced & & $9.67 \pm 2.96$ & $11.41 \pm 3.09$ & $23.85 \pm 10.22$ & $12.20 \pm 2.91$ \\
Young-inexperienced & & $6.32 \pm 0.91$ & $6.94 \pm 1.77$ & $6.74 \pm 1.68$ & $14.73 \pm 1.31$ \\
& & $8.28 \pm 2.80$ & $7.44 \pm 2.27$ & $8.30 \pm 2.16$ & $7.33 \pm 1.41$ \\
\hline
\end{tabular}

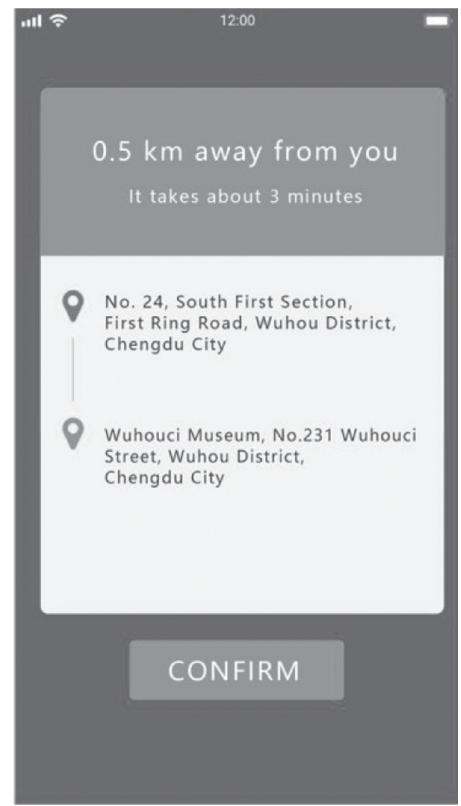

(a)

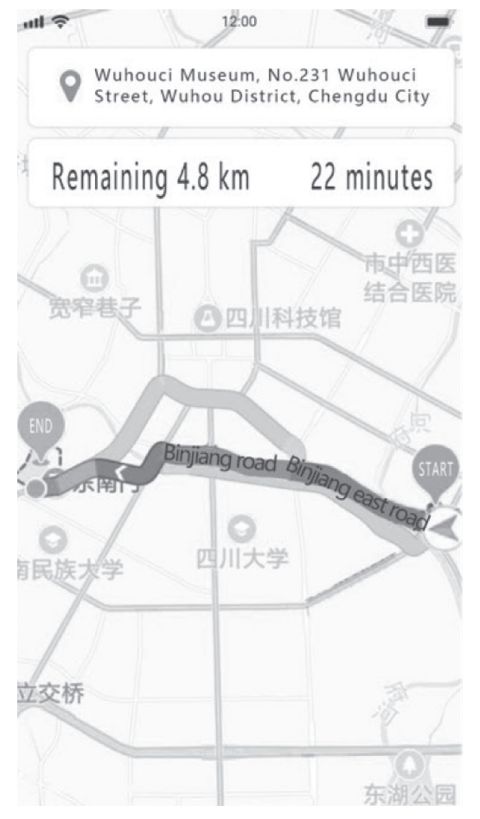

(b)

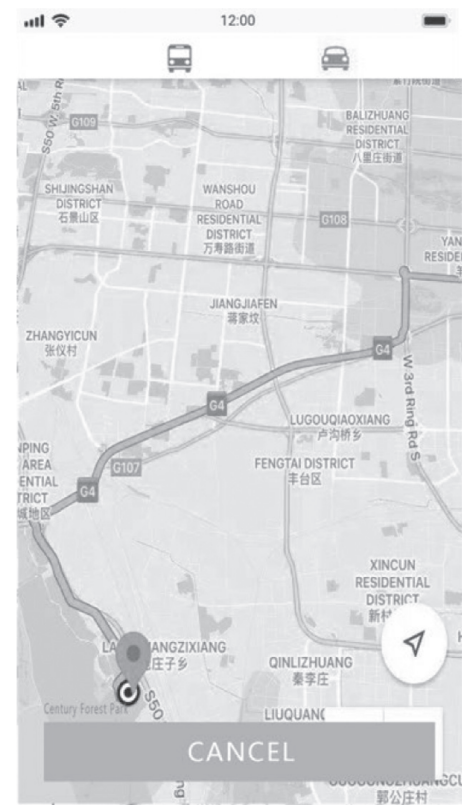

(c)

Figure 2: The interface of three experimental demos. (a) Ordering. (b) Information check. (c) Destination search.

disappeared (Figure 2(a)), and data collection was over. The content of the information should be reported verbally by the participants. Performing this task needed a small amount of finger click interaction and visual interaction; T2: route checking: the participant checked the route information on the phone screen visually when driving as he heard "Look" (the route information provides such information as the distance from the target and direction of the route) (Figure 2(b)), and data collection began. After confirming the information, the participant reported "OK," and the data collection was finished. Only visual interaction was required by this task. However, information such as route information should be memorized. T3: destination search: the participant immediately checked the route information on the phone screen, and data collection began when driving as he heard "Look." The destination was off-screen, so the participant should move the marked destination icon to the screen (peeping window) [61] by dragging or zooming (based on personal habits) (Figure 2(c)). After confirming the information, the participant reported "OK," and the data collection was finished. A relatively high level of finger and visual interactions is required by this task. Following the completion of each task, the cognitive load and satisfaction scales were completed. There was a three-minute rest time for the participants following the completion of the questionnaire.

(4) In order to obtain the performance data in the driving state and compare it with the parked state, the participants were asked to drive at $40-50 \mathrm{~km} / \mathrm{h}$ normal speed in a typical a Chinese urban two-lane road with low traffic load. They were tested using baseline tests, including braking without mobile phone interaction. Following five minutes of normal driving, T1/T2/T3 tasks were tested in the participants while driving. The test method was the same as in Step 3. There was a three-minute rest time for the participants following the completion of the questionnaire. 


\section{Results}

4.1. Interaction Performance. In this part of the study, the influence of driver's age (old vs. young) and experience (with vs. without prior knowledge of ride-hailing apps) on the driver's ability to perform the set tasks (T1/T2/T3) was analyzed. For the parameters that satisfied the normal distribution test and the homogeneity test of variances, such as interaction time and satisfaction, we used the two-way ANOVA. Furthermore, an independent sample Kruskal-Wallis nonparametric test (Shapiro Wilk normal test results: $P<0.05$ ) was used to analyze the parameters that did not satisfy the normal distribution test, like interaction error.

4.1.1. Interaction Time. With regard to interaction time, the results showed that while parked, age and experience has a significant effect on the time required to complete tasks: T1 $(F(1,44)=28.110 ; P \leq 0.001)$ and T3 $(F(1,44)=43.619$; $P \leq 0.001)$. In other words, the interaction time of young drivers is far shorter than that of old drivers (Table 1). Furthermore, when the task was completed while driving the $\mathrm{T} 1$ task, the interaction time in the young group was nearly three times shorter than that in the old group (Figure 3(a)). Age $(F(1,44)=37.842 ; P \leq 0.001)$ and experience $(F(1,44)=$ 72.369; $P \leq 0.001)$ also had significant effects on interaction time for task T3 while driving. Specifically, the interaction time of old drivers is almost $60 \%$ longer than that of young drivers (17.66 \pm 7.49 vs. $11.03 \pm 4.01$; Figure 3(a)). Counterintuitively, the interaction time for experienced drivers $(18.93 \pm 6.32)$ is higher than that of inexperienced drivers $(9.76 \pm 3.34$; Figure $3(b))$. Overall, the interaction time of old, experienced drivers was the highest, while that of young, inexperienced drivers was the lowest. The interaction time of old, experienced drivers was 3.16 times that of young, inexperienced drivers $(23.133 \pm 6.60 \quad$ vs. $7.33 \pm 1.41$; Figure 3(c)).

4.1.2. Satisfaction. In addition to interaction time, driver satisfaction was analyzed for the influence of driver's age and experience. The results showed that the driver's age and experience had no significant effect on satisfaction tasks T1 and T3. In the T2 task while driving, experience $(F(1,44)=$ 10.301; $P=0.002)$ showed significant impact on satisfaction (Figure 4). Specifically, drivers with prior knowledge of carsharing software $(7.24 \pm 1.44)$ had marginally lower satisfaction in $\mathrm{T} 2$ when compared to inexperienced drivers $(8.45 \pm 1.17)$.

4.1.3. Cognitive Load. The results showed that the interaction of age and experience significantly impacted cognitive load in driving T2 task $(F(1,44)=10.844 ; P=0.002$; Figure 5). Interestingly, young-experienced drivers had the highest cognitive load $(5.98 \pm 1.12)$, and young-inexperienced drivers had the lowest cognitive load $(2.99 \pm 0.88)$, while elderly drivers fell in-between with less dependence on experience.
4.1.4. Interaction Error. Finally, we analyzed the number of interaction errors as a function of age and driver experience. It is found that age $(z=-3.164 ; P=0.002)$ had a significant effect on T2 task interaction error under parked conditions. Table 2 shows the frequency and percentage of the error. Based on Table 2, the nonparametric test shows that the median error of old drivers $[1(0,1.75)]$ is higher than that of young drivers $[0(0,0)]$.

4.2. Distraction from Driving. In this part of the study, we analyzed the influence of driver's age and experience on how distracting the actual ride-sharing application was when performing the tasks. As mentioned previously, the performance parameters of driving distraction included average speed, the number and magnitude of steering wheel corrections, driving errors, the drives' reaction time, and the overall time taken to brake. For the parameters that satisfied the normal distribution test and the homogeneity test of variance, such as car speed deviation, we used the two-way ANOVA. Furthermore, an independent sample Kruskal-Wallis nonparametric test (Shapiro Wilk normal test results: $P<0.05$ ) was used to analyze the parameters that did not satisfy the normal distribution test, like driving error.

4.2.1. Car Speed Deviation. The interplay of age and previous experience with car-sharing software had no significant impact on speed deviation during task completion $(F=2.295, P=0.137)$.

\subsubsection{Steering Wheel Correction Amplitude and Frequency.} We found that when drivers did not use car-sharing software, experience exerted a significant impact on the number of steering wheel adjustments $(z=-5.62, P \leq 0.001)$. As shown in Table 3 , the steering wheel adjustment times of inexperienced drivers were $[2.5(2,3)]$ more than $[0.5(0,1)]$ of experienced drivers. When operating car-sharing software, the steering wheel adjustment times of drivers with different driving experiences under the T1 task were significantly different $(z=-2.959, P=0.003)$, and the steering wheel adjustment times of experienced drivers were fewer (Table 4). Remarkably, age exerted no significant impact on the steering wheel correction frequency when car-sharing software was not used. However, when operating the carsharing task T1, age significantly affected the steering wheel correction frequency $(z=-2.595, P=0.009)$, as shown in Table 4 . Moreover, the correction frequency of older drivers $[3(3,4)]$ was higher than that of younger drivers $[2(2,3)]$.

As one may expect, age plays a significant role in the average magnitude of steering wheel corrections $(F=10.928$, $P=0.002$; Table 5). Specifically, the amplitude for young drivers was almost $30 \%$ smaller than that of elderly drivers $(6.87 \pm 2.22)$ compared to $(9.63 \pm 4.36)$ (Figure $6(\mathrm{a}))$, respectively. As one might expect, the size of corrections for experienced drivers was considerably smaller $(6.38 \pm 2.08)$ than that for inexperienced drivers $(10.13 \pm 4.03)$, as shown in Figure 6(b). When driving and attempting to complete the various tasks in the app, the steering wheel correction 


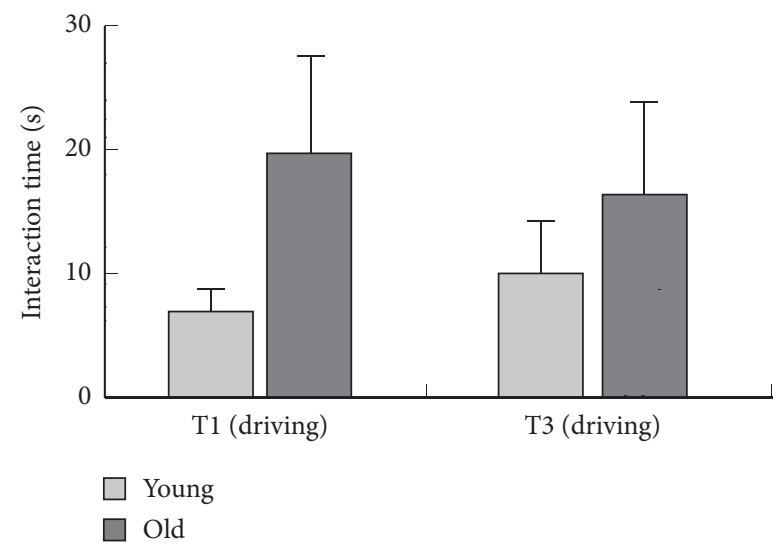

(a)

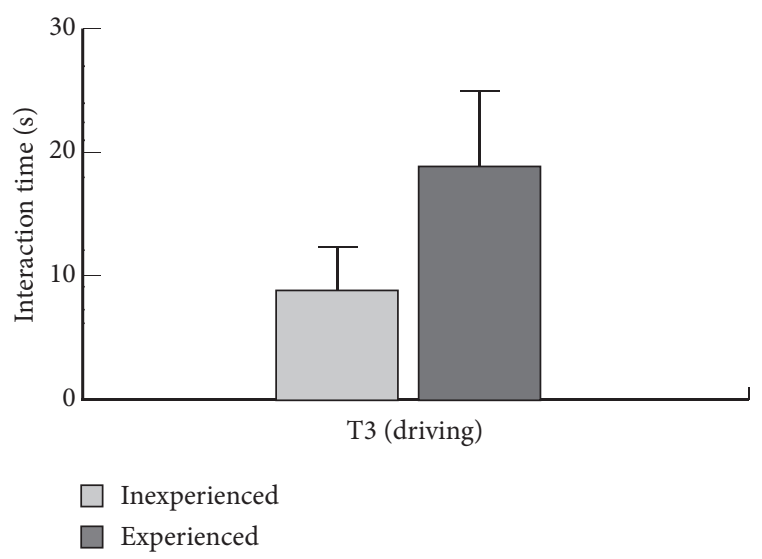

(b)

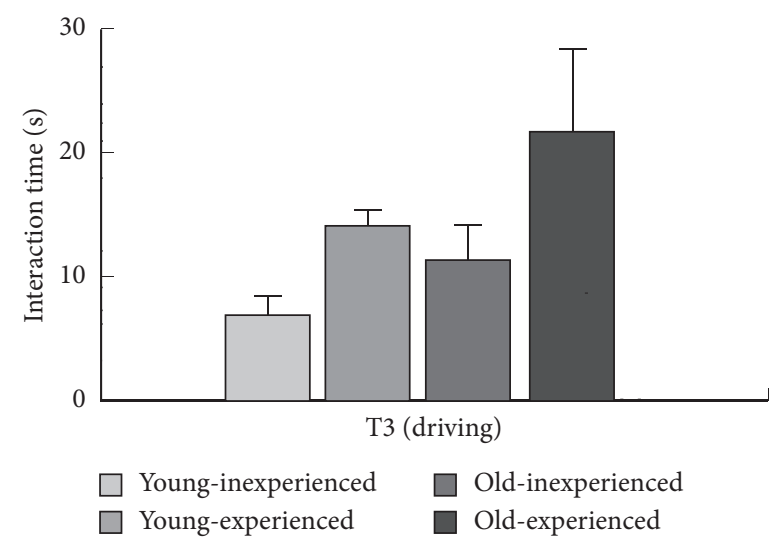

(c)

FIGURE 3: Interaction time results: (a) the interaction time of old and young drivers. (b) The interaction time of experienced vs. inexperienced drivers and (c) the interaction time of all four groups).

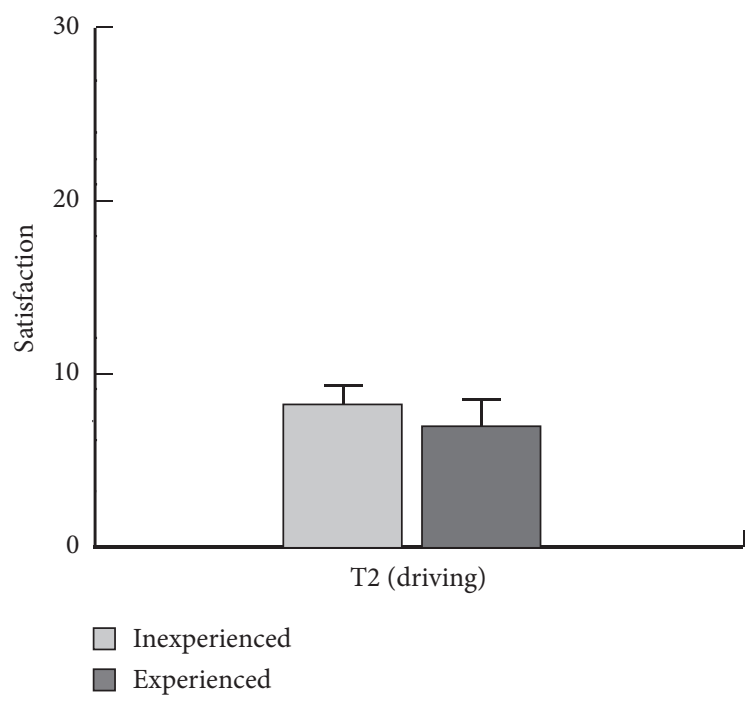

FIgURE 4: Satisfaction in different experience.

amplitude of experienced drivers was significantly smaller than that of inexperienced drivers in tasks $\mathrm{T} 1(F=17.242$, $P \leq 0.001)$ and T2 $(F=29.192, P \leq 0.001$; Figure $6(\mathrm{c}))$.
4.2.3. Driving Error. As shown in Table 6, age $(z=-3.015$, $P=0.003)$ exerted a significant impact on driving errors without using car-sharing software. Elderly $[1(0,1)]$ were 


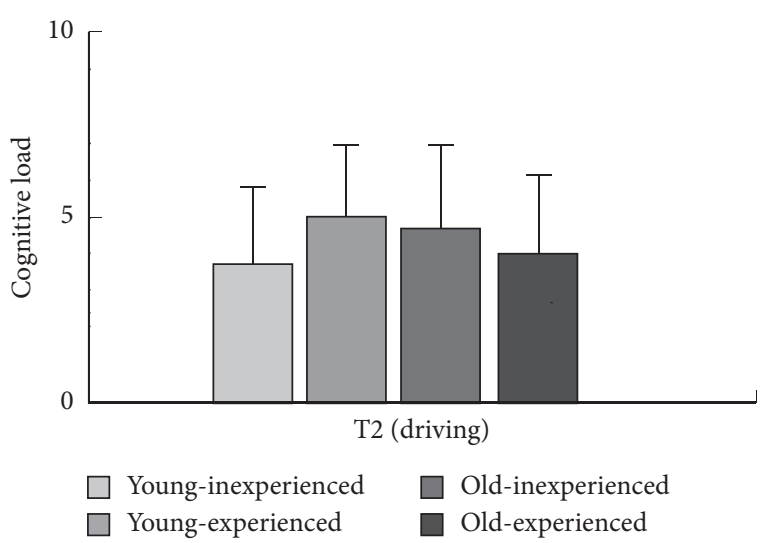

Figure 5: Cognitive load of interaction of age and experience.

TABle 2: Descriptive statistics of frequency and percentage of interaction errors among different ages.

\begin{tabular}{lcccc}
\hline Interaction errors & 0.00 & 1.00 & 2.00 & 3.00 \\
\hline Young & $10(41.7 \%)$ & $8(33.3 \%)$ & $4(16.7 \%)$ & $2(8.3 \%)$ \\
Old & $20(83.3 \%)$ & $4(16.7 \%)$ & $0(0.0 \%)$ & $0(0.0 \%)$ \\
\hline
\end{tabular}

more likely to make mistakes than young people $[0(0,0)]$; when using car-sharing software, age $(z=-2.504, P=0.012)$ exerted a significant impact on driving errors, and elderly [1 $(0,2)]$ were more likely to make mistakes than young people [0 $(0,1)]$.

Without using car-sharing software, driving experience exerted no significant effect on driving errors. When using car-sharing software, driving experience $(z=-2.504$, $P=0.012)$ significantly impacted driving errors. The inexperienced $[1(0,2)]$ were more likely to make mistakes than the experienced $[0(0,1)]$, as shown in Table 6 . Furthermore, the use of car-sharing software widened the gap brought by experience.

4.2.4. Braking Response Time-Braking Stop Time. Finally, we analyzed the influence of driver's age and experience of carsharing software on braking response time and braking stop time. As shown in Table 7, for braking response time, when operating car-sharing software while driving, age exerted a significant effect on the braking response time in $\mathrm{T} 1$ $(F=15.163, P \leq 0.001)$ and $\mathrm{T} 2(F=13.218, P=0.001)$ tasks. In particular, young drivers' response time was shorter than that of old drivers in T1 and T2 tasks (Figure 7(a)).

When the car-sharing software was operated while driving, age exerted a significant impact on the braking stop time in the T2 $(F=15.287, P \leq 0.001)$. Specifically, in T2 task, the braking stop time of young drivers was shorter than that of old drivers (Figure $7(\mathrm{~b})$ ). When not using car-sharing software, the experience of car-sharing software significantly impacted the braking time $(F=12.463, P=0.001)$. In addition, the braking time of the experienced group was shorter [3.16 (1.05)], and that of the inexperienced group was larger [3.28 (1.12)]. In the T3 task, car-sharing software experience exerted a significant impact on braking stop time $(F=41.314$, $P \leq 0.001)$. Specifically, the time of experienced drivers was longer than that of inexperienced drivers. Most shockingly, experienced drivers who had the shortest braking stop time when not operating their phones took nearly twice as long as normal to brake when trying to complete this task, Figure 7(c).

\section{Discussion}

5.1. The Influence of Driver Age and Prior App Experience on Car-Sharing Software Usability. As one might expect, the interaction efficiency decreased, and the number of interaction errors increased in elderly drivers when compared to the younger participants, even before considering the effects of complicating their jobs by asking them to perform tasks within the app; this does not corroborate the research primarily focusing on the task of using SMS and telephone in the car [25], which demonstrates that although the interaction tasks of car-sharing software and SMS and phone tasks belong to the task of MPDD, the consequences are different, thereby necessitating the research of different mobile phone interaction tasks. Interestingly, while the gap in interaction efficiency for the different age groups widened when these additional tasks were included, the gap actually narrowed for the number of errors performed by the two groups, which was mainly caused by the increase of interaction errors among young people. Scott-Parker and Oviedo-Trespalacios reported that young people are more "careless" about using mobile phones in cars and are prone to car accidents [16]. However, Caird et al. [22] reported that the elderly are more vulnerable to phone interaction while driving, which could elucidate the difference between carsharing interaction tasks and other MPDD tasks. However, it could also be caused by ethnic factors, which warrants further confirmation by the comparative follow-up study of different races. When driving without using car-sharing software, the interaction time of the elderly is 1.43 times longer than that of the young people, but when they were asked to perform a task within the app, the interaction time of the elderly increased to nearly three times that of the young drivers. Furthermore, the number of the elderly' interaction errors in the T2 task was more than that of the young when parked. However, when driving and performing tasks in the app, there is no significant difference in the number of errors between the elderly and young subjects, suggesting that young people are more easily distracted by the car-sharing software or are less cautious when multitasking, which are possibly skills one gains with age.

One unexpected result was that a driver's prior knowledge of the ride-sharing app actually had a negative impact on the efficiency of their interactions and overall satisfaction. In terms of subjective usability, drivers with previous experience were generally less satisfied than inexperienced drivers and were no quicker than interaction time. Inexperienced drivers performed the interactive tasks faster than experienced drivers. Specifically, experienced drivers' interaction time is two times higher than that of inexperienced drivers, which may be due to the "recklessness" of inexperienced drivers and the relative "caution" of experienced drivers. Indeed, behavioral observations during 
TABLE 3: Descriptive statistics of frequency and percentage of steering wheel correction frequency among different experience levels without operating car-sharing software.

\begin{tabular}{|c|c|c|c|c|c|c|c|c|}
\hline Frequency & & 0 & 2 & 3 & 4 & 5 & $z$ & $P$ \\
\hline Experienced/inexperienced & $\begin{array}{l}\text { Experienced } \\
\text { Inexperienced }\end{array}$ & $\begin{array}{l}12(50 \%) \\
0(0.0 \%)\end{array}$ & $\begin{array}{c}0(0.0 \%) \\
8(33.3 \%)\end{array}$ & $\begin{array}{c}0(0.0 \%) \\
8(33.3 \%)\end{array}$ & $\begin{array}{c}0(0.0 \%) \\
3(12.5 \%)\end{array}$ & $\begin{array}{l}0(0.0 \%) \\
1(4.2 \%)\end{array}$ & -5.62 & $\leq 0.0011$ \\
\hline
\end{tabular}

TABle 4: Descriptive statistics of frequency and percentage of steering wheel correction frequency among different ages and experience levels in the $\mathrm{T} 1$ task.

\begin{tabular}{|c|c|c|c|c|c|c|}
\hline Frequency & & 0.00 & 1.00 & 2 & 3.00 & 4.00 \\
\hline \multirow{2}{*}{ Experienced/inexperienced } & Experienced & $2(8.3 \%)$ & $1(4.2 \%)$ & $11(45.8 \%)$ & $9(37.5 \%)$ & $1(4.2 \%)$ \\
\hline & Inexperienced & $0(0.0 \%)$ & $2(8.3 \%)$ & $4(16.7 \%)$ & $8(33.3 \%)$ & $2(8.3 \%)$ \\
\hline \multirow{2}{*}{ Young/old } & Young & $2(8.3 \%)$ & $0(0.0 \%)$ & $2(8.3 \%)$ & $13(54.2 \%)$ & $3(12.5 \%)$ \\
\hline & Old & $0(0.0 \%)$ & $3(12.5 \%)$ & $13(54.2 \%)$ & $4(16.7 \%)$ & $0(0.0 \%)$ \\
\hline \multicolumn{2}{|l|}{ Frequency } & 7 & 8.00 & 10 & 11 & 12 \\
\hline \multirow{2}{*}{ Experienced/inexperienced } & Experienced & $0(0.0 \%)$ & $0(0.0 \%)$ & $0(0.0 \%)$ & $0(0.0 \%)$ & $0(0.0 \%)$ \\
\hline & Inexperienced & $1(4.2 \%)$ & $1(4.2 \%)$ & $2(8.3 \%)$ & $1(4.2 \%)$ & $3(12.5 \%)$ \\
\hline \multirow{2}{*}{ Young/old } & Young & $0(0.0 \%)$ & $0(0.0 \%)$ & $0(0.0 \%)$ & $1(4.2 \%)$ & $3(12.5 \%)$ \\
\hline & Old ${ }^{\circ}$ & $1(4.2 \%)$ & $1(4.2 \%)$ & $2(8.3 \%)$ & $0(0.0 \%)$ & $0(0.0 \%)$ \\
\hline
\end{tabular}

TABLE 5: Descriptive statistics of mean and standard deviation of steering wheel correction amplitude among different ages and experience levels.

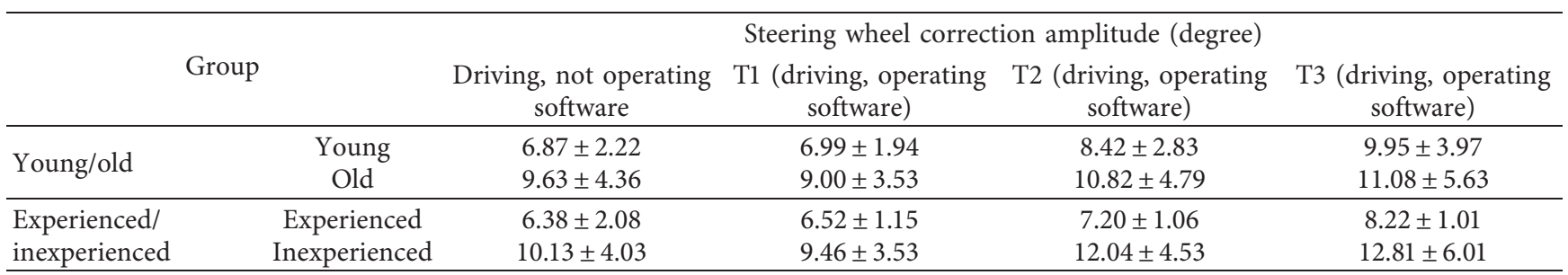

the experiment support this, as the more experienced drivers paused during the interaction process to look at the road and confirm it was safe to continue acting. They would return their attention to the mobile phone. Furthermore, in interviews conducted after the experiment, it was also found that experienced drivers took a more cautious stance on performing the tasks, stating that "interactive tasks are not so urgent; there is no need to complete too quickly." On the other hand, inexperienced drivers tried their best to complete the task as soon as possible, with fewer similar behaviors and feedback in postsimulation interviews.

Regarding user satisfaction, experienced drivers were less satisfied than inexperienced drivers. After the experiment, experienced drivers conveyed in interviews the specific causes of dissatisfaction, such as "when used in practice, too long information will lead to memory." Most inexperienced drivers found it difficult to point out the specific reasons for their dissatisfaction. Therefore, lower satisfaction may be due to experienced drivers' better understanding of car-sharing software's shortcomings.

When considering the interplay of age and experience, young, inexperienced drivers had the lowest cognitive load, one-third of older, experienced drivers, who took the longest to complete most tasks. Overall, under the combined strains of driving and using mobile devices, the increased cognitive load was the same as the negative change trend of most indicators analyzed in this study. The time taken to complete a given task and the overall efficiency of the actions are likely to improve driver safety and should be of considerable concern to the app developers. While young, inexperienced drivers had the lowest cognitive load, their more old and experienced counterparts had the highest cognitive load, which may be because young, inexperienced drivers are not aware of some risks when attempting multitasking.

5.2. The Influence of Age and Experience on Distraction Susceptibility. Not only did young drivers outperform the elderly subjects in terms of app usability, but they also had fewer driver errors (in line with Haque \& Washington [43]), smaller steering wheel corrections, and faster braking times when operating their car, which is consistent with the findings of Hancock et al. [21]. However, if one compares the performance when completing the app's set tasks, the resultant reduction in performance is more pronounced in young drivers. As young drivers performed smaller corrections to their steering wheels when driving without operating car-sharing software, when using the app, the differences caused by age disappeared. Although young people have better control normally, using their mobile phones while driving drastically reduces these advantages. Interestingly, regarding the effect of driver's age, the stopping time reflects a trend opposite to other variables, and the stopping times of drivers of any age are comparable under 


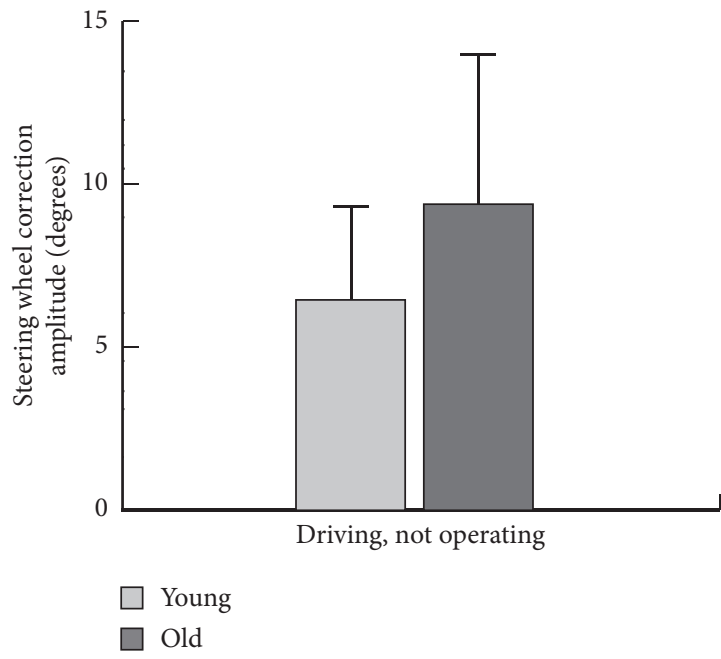

(a)

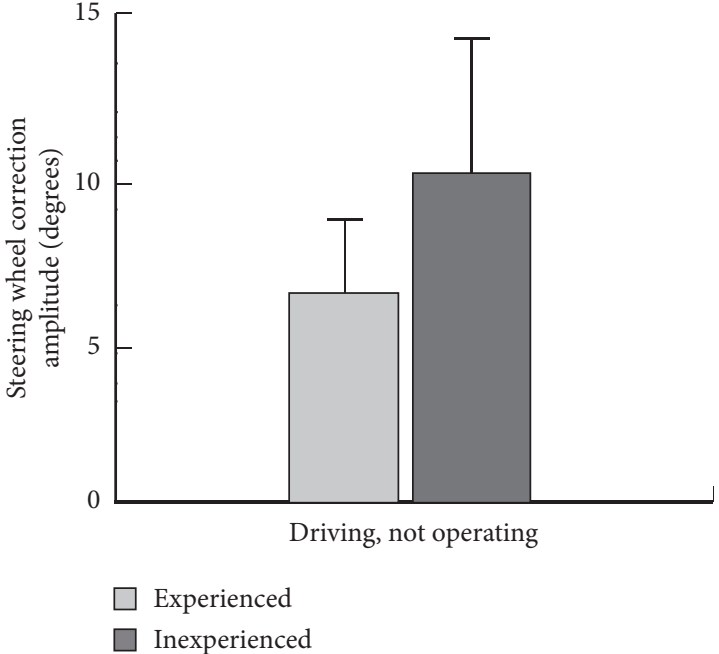

(b)

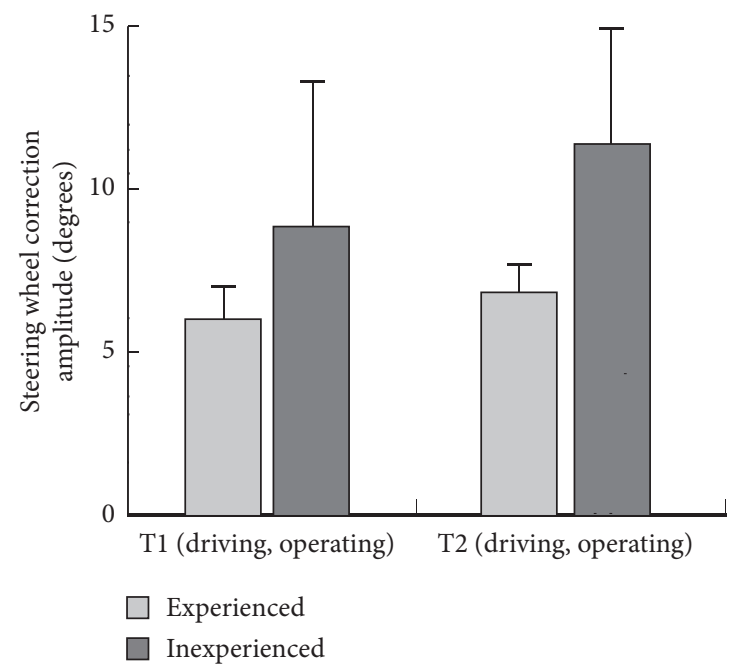

(c)

FiguRE 6: Steering wheel correction amplitude. The steering wheel correction amplitude of (a) different ages and (b) different experience levels. (c) The steering wheel correction amplitude of experienced and inexperienced drivers while driving and using car-sharing software.

TABle 6: Descriptive statistics of frequency and percentage of driving error among different ages and experience levels.

\begin{tabular}{|c|c|c|c|c|c|c|c|c|}
\hline Frequency & & 0.00 & 1.00 & 2.00 & 4.00 & 5.00 & $z$ & $P$ \\
\hline Without operating car-sharing software & $\begin{array}{l}\text { Old } \\
\text { Young }\end{array}$ & $\begin{array}{l}10(41.7 \%) \\
20(83.3 \%)\end{array}$ & $\begin{array}{c}12(50.0 \%) \\
4(16.7 \%)\end{array}$ & $\begin{array}{l}2(8.3 \%) \\
0(0.0 \%)\end{array}$ & $\begin{array}{l}\text { Null } \\
\text { Null }\end{array}$ & $\begin{array}{l}\text { Null } \\
\text { Null }\end{array}$ & -3.015 & 0.003 \\
\hline T1 task & $\begin{array}{c}\text { Old } \\
\text { Young }\end{array}$ & $\begin{array}{c}8(33.3 \%) \\
14(58.3 \%) \\
\end{array}$ & $\begin{array}{c}8(33.3 \%) \\
10(41.7 \%) \\
\end{array}$ & $\begin{array}{c}4(16.7 \%) \\
0(0.0 \%) \\
\end{array}$ & $\begin{array}{c}3(12.5 \%) \\
0(0.0 \%)\end{array}$ & $\begin{array}{l}1(4.2 \%) \\
0(0.0 \%)\end{array}$ & -2.504 & 0.012 \\
\hline $\mathrm{T} 1$ task & $\begin{array}{c}\text { Experienced } \\
\text { Inexperienced }\end{array}$ & $\begin{array}{c}14(58.3 \%) \\
8(33.3 \%)\end{array}$ & $\begin{array}{c}10(41.7 \%) \\
8(33.3 \%)\end{array}$ & $\begin{array}{c}0(0.0 \%) \\
4(16.7 \%)\end{array}$ & $\begin{array}{c}0(0.0 \%) \\
3(12.5 \%)\end{array}$ & $\begin{array}{l}0(0.0 \%) \\
1(4.2 \%)\end{array}$ & -2.504 & 0.012 \\
\hline
\end{tabular}

normal driving conditions (no significant difference), but with the distractions of car-sharing software, older drivers' stopping behavior will be more impaired (significantly higher than that of young drivers). This is supported by the findings of Hancock et al. [21].

When one considers car-sharing software experience, one finds that drivers with previous knowledge performed significantly better than the inexperienced subjects in all driving safety parameters, as one might expect. Steering wheel correction amplitudes were greater for inexperienced drivers when completing the tasks and under normal driving conditions. Not only were the adjustments more frequent for inexperienced drivers, but they made five times more adjustments when driving without operating their phones. 
TABlE 7: Descriptive statistics of mean and standard deviation of response time and braking stop time among different age and experience.

\begin{tabular}{|c|c|c|c|c|c|}
\hline Group & & $\begin{array}{l}\text { Driving, not operating } \\
\text { software }\end{array}$ & $\begin{array}{l}\text { T1 (driving, operating } \\
\text { software) }\end{array}$ & $\begin{array}{l}\text { T2 (driving, operating } \\
\text { software) }\end{array}$ & $\begin{array}{c}\text { T3 (driving, operating } \\
\text { software) }\end{array}$ \\
\hline \multicolumn{6}{|c|}{ Response time (s) } \\
\hline \multirow{2}{*}{ Young/old } & Young & $0.76 \pm 0.23$ & $0.73 \pm 0.23$ & $0.65 \pm 0.25$ & $0.94 \pm 0.53$ \\
\hline & Old & $0.64 \pm 0.32$ & $1.04 \pm 0.40$ & $1.05 \pm 0.47$ & $1.17 \pm 0.73$ \\
\hline \multirow{2}{*}{$\begin{array}{l}\text { Experienced/ } \\
\text { inexperienced }\end{array}$} & Experienced & $0.74 \pm 0.20$ & $1.06 \pm 0.30$ & $0.77 \pm 0.28$ & $1.02 \pm 0.46$ \\
\hline & Inexperienced & $0.67 \pm 0.35$ & $0.72 \pm 0.33$ & $0.93 \pm 0.52$ & $1.08 \pm 0.80$ \\
\hline \multicolumn{6}{|c|}{ Braking stop time (s) } \\
\hline \multirow{2}{*}{ Young/old } & Young & $3.0 \pm 0.80$ & $3.65 \pm 1.08$ & $2.70 \pm 0.80$ & $4.53 \pm 1.49$ \\
\hline & Old & $3.2 \pm 1.11$ & $4.22 \pm 0.94$ & $3.74 \pm 1.08$ & $4.15 \pm 2.23$ \\
\hline \multirow{2}{*}{$\begin{array}{l}\text { Experienced/ } \\
\text { inexperienced }\end{array}$} & Experienced & $2.7 \pm 0.40$ & $3.64 \pm 0.92$ & $3.16 \pm 1.05$ & $5.62 \pm 1.69$ \\
\hline & Inexperienced & $3.59 \pm 1.14$ & $4.23 \pm 1.09$ & $3.28 \pm 1.12$ & $3.07 \pm 1.03$ \\
\hline
\end{tabular}

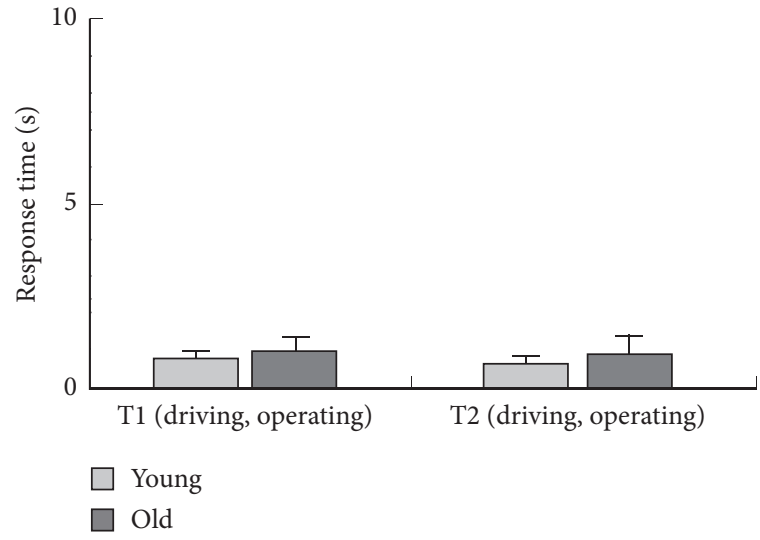

(a)

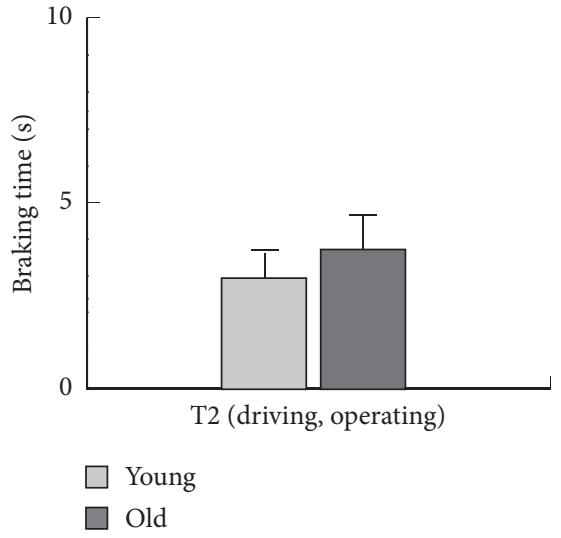

(b)

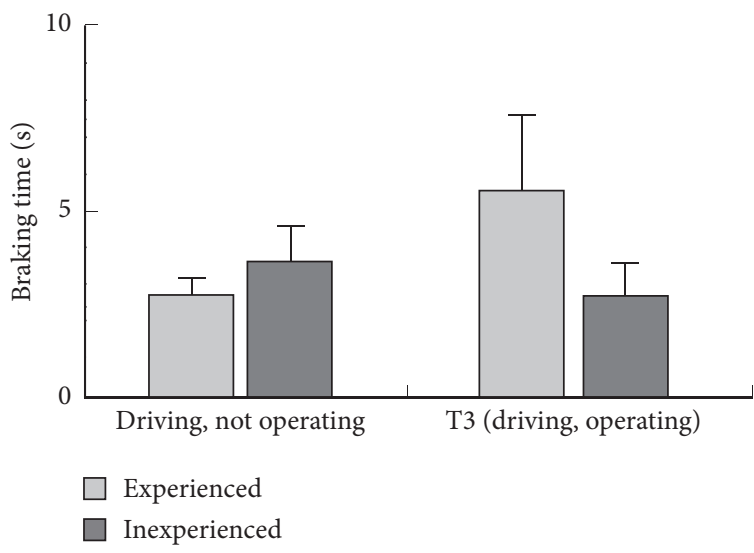

(c)

FIGURE 7: Impact of age and experience on response time and braking stop time. (a) The response time and (b) the braking stop time of different ages while operating car-sharing software. (c) The braking stop time of experienced and inexperienced drivers while driving with car-sharing software.

However, when operating car-sharing software while driving, the gap was reduced to less than two times as many adjustments, mainly caused by the increase of experienced drivers' errors, strongly suggesting that the app dramatically impacts anybody's ability to control the car.

Inexperienced drivers also had more driving errors than experienced drivers. Furthermore, experienced drivers were quicker to come to a stop when not using their phones, but the app resulted in experienced drivers taking more time than inexperienced drivers to stop. According to our followup interviews, this may be due to some degree of "calmness" felt by experienced drivers, who have encountered similar situations many times in real-life. They believe that sudden braking is more likely to cause accidents such as being rearended or causing injuries to passengers in the car, so they will be more cautious and gentler in braking. Conversely, for 
drivers who have no experience using car-sharing software, the simultaneous use of a phone and the need to brake will make them more confused and instinctively adopt more aggressive braking behavior, hoping to slow down as soon as possible. The actual impact of these two conditions on driving safety needs to be further assessed.

However, two interesting phenomena: (1) drivers who have car-sharing software previously perform better than drivers without prior experience, even in ordinary driving tasks, and (2) the stopping time for experienced users showed the opposite trend as all other measured parameters. The advantages demonstrated by experienced drivers may reflect that although it is recognized that distracting behavior during driving is harmful to safety, to some extent, driving while using a phone is also a kind of training and may promote the driver's driving ability once suitably adapted, but this conjecture needs further research to prove.

Finally, we looked at the combined effects of age and experience. It was shown that young, inexperienced drivers performed the worst in driving safety, as one might expect, but they had the lowest cognitive load and the highest app interaction efficiency. Furthermore, differences in average speed tests suggest that young inexperienced drivers may lack the sense of safety possessed by their older, more experienced counterparts and pay too much attention to interactive tasks.

\section{Conclusions}

This study demonstrates that car-sharing software exerts a significant negative impact on safety; thus, drivers should avoid operating a car-sharing program during driving. However, car-sharing drivers always use mobile phones, which is also legally allowed in some countries. Thus, it is essential to explore the use of car-sharing software while driving and support car-sharing software optimization, screening, and training of car-sharing drivers to maximize traffic safety.

Young driver's overall performance in terms of susceptibility to distractions and app usability is better than that of the elderly. However, car-sharing tasks make it easier for young drivers to make mistakes while driving, which to some extent narrows the performance gap that results from age. Thus, younger drivers have better safety control ability and interaction efficiency; however, it is necessary to train young drivers in car-sharing software interaction to augment the stability of their driving interaction.

In most aspects of interaction performance and driving safety performance, experienced drivers perform better than inexperienced drivers and have an in-depth understanding of car-sharing software weaknesses, except for brake time and interaction time; according to behavior observation and postinterview, this is attributable to the "recklessness" of inexperienced drivers and the relative "prudence" and "calmness" of experienced drivers. Inexperienced drivers are more likely to focus on the interaction behavior and ignore the main driving task, and they are more likely to take drastic braking behavior. Thus, in car-sharing software optimization design, we cannot blindly pursue the improvement of interaction efficiency. In the car-sharing software user evaluation, experienced drivers will give a low evaluation but highlight the specific pain points.

As expected, young, inexperienced drivers perform worst in driving safety but have the lowest cognitive load and the most efficient interaction. Hence, drivers (especially young inexperienced ones), who lack experience in the use of car-sharing software, need to focus on driving safety training before taking up their posts and restrict their opportunities to operate car-sharing software in the software client design and training.

Remarkably, drivers with car-sharing software experience perform better than inexperienced drivers, even in driving tasks that do not require the use of software; this could reflect that, to a certain extent, using car-sharing software while driving is also a type of training, and once properly adapted, it could enhance the driving ability of drivers.

In a practical sense, this study provides more precise screening criteria and training references for car-sharing drivers of different ages and experiences, such as providing targeted training programs for young drivers to increase their "driving endurance" to enhance the training efficiency and effect. In addition, this study provides a basis for the optimization design of car-sharing software for different user groups. For example, owing to the long interaction time of elderly drivers, the interaction process with fewer interaction steps can be customized. Theoretically, because of car-sharing, which lacks research, two-way research on the combination of driving safety and interactive usability due to people's age and experience was conducted, compared with the existing research, and further enriched the types of human factors research on the use of mobile phones in cars; this is helpful in enhancing the security of car-sharing and the availability of car-sharing applications. However, due to various limitations, there is still room for improvement. For example, currently, only male drivers have been tested. Hence, in the future, the influence of gender on the use of car-sharing software will be examined. Additionally, one could extend the range of tasks in the app performed while driving to validate that the effects seen here are not a result of the specific tasks but are representative of using a mobile phone while driving. Besides, comparative studies on tasks (T1/T2/T3) will be presented in other papers because of space constraints. Further research on this subject could shed light on the impact of age and prior experience on driving safety, helping to future-proof the industry as populations around the world continue to age.

\section{Data Availability}

No additional data were used to support this study.

\section{Conflicts of Interest}

The authors declare that there are no conflicts of interest regarding the publication of this paper. 


\section{Acknowledgments}

The authors would like to acknowledge the fund provided by the MOE Layout Foundation of Humanities and Social Sciences (grant no. 19YJA760094); Sichuan Social Science Planning Fund Program: Sichuan Statistical Development Special Project (grant no. SC20TJ031); the Fundamental Research Funds for the Central Universities (grant nos. A0920502052001-210); MOE Industry-University Collaborative Education Program (grant no. 202002035011); and CES-Kingfar Excellent Young Scholar Joint Research Funding (grant no. CES-Kingfar-2019-001);

\section{References}

[1] H. Shabeer and W. Banu, "Mobile phone accidents - experience of India," Transport and Telecommunication Journal, vol. 13, no. 3, pp. 193-208, 2012.

[2] F. Prat, M. Planes, M. E. Gras, and M. J. M. Sullman, "An observational study of driving distractions on urban roads in Spain," Accident Analysis \& Prevention, vol. 74, pp. 8-16, 2015.

[3] World Health Organization, Mobile Phone Use: A Growing Problem of Driver Distraction, World Health Organization, Geneva, Switzerland, 2011.

[4] A. Bangor, P. Kortum, and J. Miller, "Determining what individual sus scores mean: adding an adjective rating scale," Journal of Usability Studies, vol. 4, no. 3, pp. 114-123, 2009.

[5] M. Zhang, "Research on emotional interaction experience of automobile facing the future," Packaging Engineering, vol. 40, no. 2, pp. 11-16, 2019.

[6] G. Rumschlag, T. Palumbo, A. Martin, D. Head, R. George, and R. L. Commissaris, "The effects of texting on driving performance in a driving simulator: the influence of driver age," Accident Analysis \& Prevention, vol. 74, pp. 145-149, 2015.

[7] P. Choudhary and N. R. Velaga, "Modelling driver distraction effects due to mobile phone use on reaction time," Transportation Research Part C: Emerging Technologies, vol. 77, pp. 351-365, 2017a.

[8] J. He, A. Chaparro, B. Nguyen et al., "Texting while driving: is speech-based text entry less risky than handheld text entry?" Accident Analysis \& Prevention, vol. 72, pp. 287-295, 2014.

[9] O. Oviedo-Trespalacios, M. M. Haque, M. King, and S. Washington, "Understanding the impacts of mobile phone distraction on driving performance: a systematic review," Transportation Research Part C: Emerging Technologies, vol. 72, pp. 360-380, 2016.

[10] C. Jing and J. Zhi, "Impact of shared tasks on vehicle safety and software usability," Journal of Southwest Jiaotong University, vol. 34, pp. 1-9, 2020, http://kns.cnki.net/kcms/detail/ 51.1277.U.20200929.1436.004.html.

[11] X. Feng, X. Zhang, Y. Zhang et al., "Research on distracted driving for taxi software [J]," China Mechanical Engineering, vol. 30, no. 15, pp. 1782-1789, 2019.

[12] W. Y. Szeto, L. Yang, R. C. P. Wong, Y. C. Li, and S. C. Wong, "Spatio-temporal travel characteristics of the elderly in an ageing society," Travel Behaviour and Society, vol. 9, pp. 1020, 2017.

[13] R. C. P. Wong, W. Y. Szeto, L. Yang, Y. C. Li, and S. C. Wong, "Public transport policy measures for improving elderly mobility," Transport Policy, vol. 63, pp. 73-79, 2018.
[14] L. Yang, "Modeling the mobility choices of older people in a transit-oriented city: policy insights," Habitat International, vol. 76, pp. 10-18, 2018.

[15] L. Yang, J. Liu, Y. Lu et al., "Global and local associations between urban greenery and travel propensity of older adults in Hong Kong," Sustainable Cities and Society, vol. 63, Article ID 102442, 2020.

[16] B. Scott-Parker and O. Oviedo-Trespalacios, "Young driver risky behaviour and predictors of crash risk in Australia, New Zealand and Colombia: same but different?" Accident Analysis \& Prevention, vol. 99, pp. 30-38, 2017.

[17] M. F. Lesch and P. A. Hancock, "Driving performance during concurrent cell-phone use: are drivers aware of their performance decrements?" Accident Analysis \& Prevention, vol. 36, no. 3, pp. 471-480, 2004.

[18] J. M. Mcdowd and F. I. M. Craik, "Effects of aging and task difficulty on divided attention performance," Journal of Experimental Psychology: Human Perception and Performance, vol. 14, no. 2, pp. 267-280, 1988.

[19] A. Håkan, K. Alm, W. Lena et al., "The effects of a mobile telephone task on driver behaviour in a car following situation," Accident Analysis \& Prevention, vol. 54, 1995.

[20] M. M. Haque and S. Washington, "A parametric duration model of the reaction times of drivers distracted by mobile phone conversations," Accident Analysis \& Prevention, vol. 62, pp. 42-53, 2014.

[21] P. A. Hancock, M. Lesch, and L. Simmons, "The distraction effects of phone use during a crucial driving maneuver," Accident Analysis \& Prevention, vol. 35, no. 4, pp. 501-514, 2003.

[22] J. K. Caird, C. R. Willness, P. Steel, and C. Scialfa, "A metaanalysis of the effects of cell phones on driver performance," Accident Analysis \& Prevention, vol. 40, no. 4, pp. 1282-1293, 2008.

[23] Y.-C. Liu and Y.-K. Ou, "Effects of age and the use of handsfree cellular phones on driving behavior and task performance," Traffic Injury Prevention, vol. 12, no. 6, pp. 550-558, 2011.

[24] P. Choudhary and N. R. Velaga, "Analysis of vehicle-based lateral performance measures during distracted driving due to phone use," Transportation Research Part F: Traffic Psychology and Behaviour, vol. 44, pp. 120-133, 2017.

[25] J. Coughlin, "Not your father's auto industry? Aging, the automobile, and the drive for product innovation," Generations, vol. 28, no. 4, pp. 38-44, 2004.

[26] N. Tractinsky, E. S. Ram, and D. Shinar, "To call or not to callThat is the question (while driving)," Accident Analysis \& Prevention, vol. 56, pp. 59-70, 2013.

[27] S. G. Klauer, "Distracted driving and risk of road crashes among novice and experienced drivers," New England Journal of Medicine, vol. 307, no. 1, pp. 54-59, 2014.

[28] S. Cao and Y. Liu, "Concurrent processing of vehicle lane keeping and speech comprehension tasks," Accident Analysis \& Prevention, vol. 59, no. 5, pp. 46-54, 2013.

[29] E. Becic, G. S. Dell, K. Bock, S. M. Garnsey, T. Kubose, and A. F. Kramer, "Driving impairs talking," Psychonomic Bulletin \& Review, vol. 17, no. 1, pp. 15-21, 2010.

[30] H. Kim and H. Song, "Evaluation of the safety and usability of touch gestures in operating in-vehicle information systems with visual occlusion," Applied Ergonomics, vol. 45, no. 3, pp. 789-798, 2014.

[31] E. Mitsopoulos-Rubens, M. J. Trotter, and M. G. Lenné, "Effects on driving performance of interacting with an invehicle music player: a comparison of three interface layout 
concepts for information presentation," Applied Ergonomics, vol. 42, no. 4, pp. 583-591, 2011.

[32] K. L. Young, E. Mitsopoulos-Rubens, C. M. Rudin-Brown, and M. G. Lenné, "The effects of using a portable music player on simulated driving performance and task-sharing strategies," Applied Ergonomics, vol. 43, no. 4, pp. 738-746, 2012.

[33] J. Engström, M. L. Aust, and M. Viström, "Effects of working memory load and repeated scenario exposure on emergency braking performance," Human Factors: The Journal of the Human Factors and Ergonomics Society, vol. 52, no. 5, pp. 551-559, 2010.

[34] D. L. Strayer and F. A. Drew, "Profiles in driver distraction: effects of cell phone conversations on younger and older drivers," Human Factors: The Journal of the Human Factors and Ergonomics Society, vol. 46, no. 4, pp. 640-649, 2004.

[35] J. L. Harbluk, Y. I. Noy, P. L. Trbovich, and M. Eizenman, "An on-road assessment of cognitive distraction: impacts on drivers' visual behavior and braking performance," Accident Analysis \& Prevention, vol. 39, no. 2, pp. 372-379, 2007.

[36] B. Mehler, B. Reimer, and J. F. Coughlin, "Sensitivity of physiological measures for detecting systematic variations in cognitive demand from a working memory task," Human Factors: The Journal of the Human Factors and Ergonomics Society, vol. 54, no. 3, pp. 396-412, 2012.

[37] J. M. Cooper, I. Vladisavljevic, N. Medeiros-Ward, P. T. Martin, and D. L. Strayer, "An investigation of driver distraction near the tipping point of traffic flow stability," Human Factors: The Journal of the Human Factors and Ergonomics Society, vol. 51, no. 2, pp. 261-268, 2009.

[38] B. Reimer, B. Donmez, M. Lavallière, B. Mehler, J. F. Coughlin, and N. Teasdale, "Impact of age and cognitive demand on lane choice and changing under actual highway conditions," Accident Analysis \& Prevention, vol. 52, no. 52, pp. 125-132, 2013.

[39] T. A. Ranney, J. L. Harbluk, and Y. I. Noy, "Effects of voice technology on test track driving performance: implications for driver distraction," Human Factors: The Journal of the Human Factors and Ergonomics Society, vol. 47, no. 2, pp. 439-454, 2005.

[40] M. E. Rakauskas, L. J. Gugerty, and N. J. Ward, "Effects of naturalistic cell phone conversations on driving performance," Journal of Safety Research, vol. 35, no. 4, pp. 453-464, 2004.

[41] B. Reimer, B. Mehler, Y. Wang, and J. F. Coughlin, “A field study on the impact of variations in short-term memory demands on drivers' visual attention and driving performance across three age groups," Human Factors: The Journal of the Human Factors and Ergonomics Society, vol. 54, no. 3, pp. 454-468, 2012.

[42] B. Reimer, B. Mehler, and B. Donmez, "A study of young adults examining phone dialing while driving using a touchscreen vs. a button style flip-phone," Transportation Research Part F: Traffic Psychology and Behaviour, vol. 23, pp. 57-68, 2014.

[43] M. M. Haque and S. Washington, "The impact of mobile phone distraction on the braking behaviour of young drivers: a hazard-based duration model," Transportation Research Part C: Emerging Technologies, vol. 50, pp. 13-27, 2015.

[44] J. K. Caird, K. A. Johnston, C. R. Willness, M. Asbridge, and P. Steel, "A meta-analysis of the effects of texting on driving," Accident Analysis \& Prevention, vol. 71, pp. 311-318, 2014.

[45] W. P. Berg and D. J. Dessecker, "Evidence of unconscious motor adaptation to cognitive and auditory distraction," Adaptive Behavior, vol. 21, no. 5, pp. 346-355, 2013.
[46] B. L. Long, A. I. Gillespie, and M. L. Tanaka, "Mathematical model to predict drivers' reaction speeds," Journal of Applied Biomechanics, vol. 28, no. 1, pp. 48-56, 2012.

[47] L. B. Nabatilan, F. Aghazadeh, A. D. Nimbarte, C. C. Harvey, and S. K. Chowdhury, "Effect of driving experience on visual behavior and driving performance under different driving conditions," Cognition, Technology \& Work, vol. 14, no. 4, pp. 355-363, 2012.

[48] S. A. Soccolich, G. M. Fitch, M. A. Perez et al., "Comparing handheld and hands-free cell phone usage behaviors while driving," Traffic Injury Prevention, vol. 15, no. 1, pp. 21-26, 2014.

[49] O. Svenson and C. J. D. Patten, "Mobile phones and driving: a review of contemporary research," Cognition, Technology \& Work, vol. 7, no. 3, pp. 182-197, 2005.

[50] F. Meng, S. C. Wong, W. Yan, Y. C. Li, and L. Yang, "Temporal patterns of driving fatigue and driving performance among male taxi drivers in Hong Kong: a driving simulator approach," Accident Analysis \& Prevention, vol. 125, pp. 7-13, 2019.

[51] M. L. Alosco, M. B. Spitznagel, K. H. Fischer et al., "Both texting and eating are associated with impaired simulated driving performance," Traffic Injury Prevention, vol. 13, no. 5, pp. 468-475, 2012.

[52] A. Eichinger and J. Kellerer, "Between laboratory and simulator: a cognitive approach to evaluating cockpit interfaces by manipulating informatory context," Cognition, Technology \& Work, vol. 16, no. 3, pp. 417-427, 2014.

[53] J. C. F. De Winter and D. Dodou, "National correlates of selfreported traffic violations across 41 countries," Personality and Individual Differences, vol. 98, pp. 145-152, 2016.

[54] I. Nakano and B. Coffey, "Vertical-horizontal differences in visual space recognition of americans and Japanese," $O p$ tometry and Vision Science, vol. 71, pp. 71-75, 1994.

[55] DIDI Employment Report 2019. https://www.sohu.com/a/ 300154464_99902126.

[56] G. Yannis, A. Laiou, P. Papantoniou et al., "Impact of texting on young drivers' behavior and safety on urban and rural roads through a simulation experiment," Journal of Safety Research, vol. 49, pp. 25-31, 2014.

[57] N. Zhao, B. Reimer, B. Mehler, L. A. D'Ambrosio, and J. F. Coughlin, "Self-reported and observed risky driving behaviors among frequent and infrequent cell phone users," Accident Analysis \& Prevention, vol. 61, pp. 71-77, 2013.

[58] R. Li, Y. V. Chen, C. Sha, and Z. Lu, "Effects of interface layout on the usability of in-vehicle information systems and driving safety," Displays, vol. 49, pp. 124-132, 2017.

[59] S. G. Hart and L. E. Staveland, "Development of NASA-TLX (task load index): results of empirical and theoretical research," Advances in Psychology, vol. 52, pp. 139-183, 1988.

[60] H. Zhang and L. Li, "Emotional exploration of barrier free elderly bathroom product design [J]," Packaging Engineering, vol. 40, no. 412, pp. 159-163, 2019.

[61] R. Rädle, H. C. Jetter, J. Müller, and H. Reiterer, "Bigger is not always better: display size, performance, and task load during peephole map navigation," in Proceedings of the SIGCHI Conference on Human Factors in Computing Systems, pp. 4127-4136, Toronto, Canada, April 2014. 